\title{
Is Local Air Quality Management a successful strategy for achieving selected EU limit values?
}

\author{
J. H. Barnes, E. T. Hayes \& J. W. S. Longhurst \\ Air Quality Management Resource Centre, \\ University of the West of England, UK
}

\begin{abstract}
This research examines the role of Local Air Quality Management Action Planning in achieving the EU limit value for nitrogen dioxide $\left(\mathrm{NO}_{2}\right)$ annual mean, focusing on those Air Quality Management Areas (AQMAs) declared in England before July 2005 for exceedences of the $\mathrm{NO}_{2}$ annual mean objective from road traffic sources. The paper describes the initial stages of the methodology, analysing the availability of Air Quality Action Plans (AQAPs) and annual mean $\mathrm{NO}_{2}$ monitoring data. The research finds an absence of government monitoring sites with adequate nitrogen dioxide data relative to the selected AQMAs, as well as an absence of AQAPs and annual progress reports. The paper concludes that Local Air Quality Management is insufficiently calibrated to provide adequate support to the achievement of the EU limit value for $\mathrm{NO}_{2}$ annual mean.
\end{abstract}

Keywords: LAQM, Action Plans, local government, $\mathrm{NO}_{2}$, air quality objectives, limit values, GIS.

\section{Introduction}

\subsection{Local Air Quality Management}

The first national Air Quality Regulations, published as a requirement of the 1995 Environment Act in December 1997, established health-based objectives for eight air pollutants (benzene, 1,3-butadiene, carbon monoxide, lead, nitrogen dioxide, ozone, particulates $\left(\mathrm{PM}_{10}\right)$ and sulphur dioxide) [1]. These objectives anticipated the limit values prescribed in the European Air Quality Framework Directive (96/62/EC) and subsequent daughter Directives (1999/30/EC, 
2000/69/EC, 2002/3/EC), and the national Air Quality Strategy set out the government's approach to meeting them [2]. According to the Strategy the government's responsibility was to create a framework for managing air quality for others to implement. Responsibility for improving air quality fell to local authorities, private industry and the Environment Agency, as regulators, and local government with responsibility for small-scale industry, local transport and planning [3]. The principle behind this subsidiarity approach is that sources are best managed at the lowest administrative level to ensure resources are efficiently and proportionately targeted taking account of local conditions; "Action should be taken to improve air quality at the most appropriate level, be it international, European, national or local" [2].

At the time of the initial Strategy the government did not foresee how intractable and widespread the problem of traffic pollution would become. The 1997 Air Quality Strategy stated that universally applied policies should be sufficient to achieve the air quality objectives for most of the country and that the role of Local Air Quality Management (LAQM) should be in supplementing and "fine tuning" central policies at local hotspots where national measures would be too blunt or expensive [2]. The Strategy predicted that emissions and fuel quality standards would almost achieve the lower threshold of the estimated $48-62 \%$ NOx emissions reductions required to meet the $2005 \mathrm{NO}_{2}$ objective deadline, but that more stringent standards, and a reliance on local measures, would be required to prevent a renewed increase in emissions resulting from the predicted growth in vehicle use post-2010. Although the predicted post-2010 growth in UK vehicle use has stalled [4], with 93\% of the UK's Zones and Agglomerations in breach of the EU limit value for $\mathrm{NO}_{2}$ annual mean, it is apparent that national policies have not achieved as much as predicted [5], placing an increased onus on local authorities' to improve air quality.

\subsection{Local Air Quality Action Planning}

The 1997 Air Quality Regulations set health-based air quality objectives that local authorities were to work towards achieving by $31^{\text {st }}$ December 2005 . Failure to meet these objectives by the deadline required local authorities to declare, as a minimum, the area(s) of technical exceedence as an Air Quality Management Area (AQMA) and to prepare an Air Quality Action Plan (AQAP) to work "in pursuit of" achieving them [2]. Air quality action planning is the means by which local authorities in the UK are required by central government to set out their intentions for working towards meeting national air quality objectives.

The first AQAPs were submitted in 1999/2000 and now some $60 \%$ of local authorities have declared one or more AQMAs, primarily for traffic-related pollutants $\left(\mathrm{NO}_{2}\right.$ and $\left.\mathrm{PM}_{10}\right)$. Despite the preparation of over 400 draft and final AQAPs over the last decade, no traffic-related AQMAs have been revoked solely on the basis of AQAP implementation [6].

This research draws on the extensive body of evidence provided by the LAQM process since 1997 to establish whether local AQAPs have been effective in their implementation and in improving air quality at a local level. By evaluating the effectiveness of individual AQAPs, it will be possible to assess 
the effectiveness and efficiency of the LAQM regime as a strategy to meet national air quality objectives and to contribute to EU air quality legislative requirements.

\section{Methodology}

119 local authorities in the UK declared AQMAs from Round 1 (i.e. within the first 3-4 years of LAQM), 91\% of which were for nitrogen dioxide $\left(\mathrm{NO}_{2}\right)$ and $74 \%$ exclusively for traffic sources. With other sources now largely regulated, traffic remains the dominant source of local air pollutants with 94\% AQMAs currently declared for exceedences of the $\mathrm{NO}_{2}$ annual mean objective relating to traffic [7]. The majority of AQMAs have been declared for $\mathrm{NO}_{2}$ annual mean, typically as a proxy for other traffic-related pollutants. Therefore, to provide a sufficient dataset for statistical analysis and to ensure the relevance and applicability of the research, the method will focus on AQMAs that have been declared for the $\mathrm{NO}_{2}$ annual mean objective on the basis of road traffic sources.

Based on experience to date, the research hypothesis is as follows:

Local Air Quality Action Plans are not successful in terms of reducing local concentrations of $\mathrm{NO}_{2}$ and therefore Local Air Quality Management will not achieve the annual mean UK air quality objective and will therefore not make an effective contribution to meeting the relevant EU limit value.

The subject of this paper is the approach taken to identify the sample of local authorities and AQMAs that have been used in this research; a task which has highlighted a number of limitations of LAQM which, it is argued, have prevented its ability to make an effective contribution to the achievement of the $\mathrm{EU}$ limit value for $\mathrm{NO}_{2}$. The methodological approach for this research is summarised in Figure 1, with the subject of this paper focusing on Steps 1a and $2 \mathrm{a}$ and $\mathrm{b}$, i.e. identifying the sample.

\subsection{Initial sample filtering}

In order to ensure a statistically robust sample, this research focused on AQMAs declared for the $\mathrm{NO}_{2}$ annual mean objective from road traffic sources, being the predominant pollutant and source. One factor that may affect the availability and comparability of data are differences between the UK's Devolved Administrations. Northern Ireland did not join the LAQM process until the latter stage of Round 2 and, although Scotland, Wales and the Greater London Authorities operate on the same basic timescale as England, their Regulations and policy guidance documents vary and so practices may not be wholly comparable. This research therefore focuses on England (excluding London) as having the largest available dataset from which to draw and the broadest applicability.

GIS shapefiles depicting historical AQMAs were obtained from Defra and mapped in ESRI ArcView. The AQMAs declared for $\mathrm{NO}_{2}$ were selected from the 2005 AQMA dataset (July 2005), as the earliest available digital dataset, 


\section{Step 1 - assess significant changes in road-contribution nitrogen dioxide within AQMAs against Round 1 baseline}

\begin{tabular}{|c|c|c|}
\hline $\begin{array}{l}\text { a) Identify AQMAs for traffic-related } \\
\mathrm{NO}_{2} \text { annual mean objective resulting } \\
\text { from Round } 1 \text { in England }\end{array}$ & $\begin{array}{l}\text { b) Establish Round } 1 \text { baseline road- } \\
\text { contribution } \mathrm{NO}_{2} \text { within AQMAs }\end{array}$ & $\begin{array}{l}\text { c) Establish road-contribution } \mathrm{NO}_{2} \text { for } \\
\text { subsequent years }\end{array}$ \\
\hline \multicolumn{3}{|c|}{ Step 2 - assess the implementation of local Action Plan measures } \\
\hline $\begin{array}{l}\text { a) Identify original Round } 1 \text { Action Plan } \\
\text { for AQMAs identified in Step } 1\end{array}$ & $\begin{array}{l}\text { b) Identify subsequent iterations of } \\
\text { AQAPs and annual AQAP Progress } \\
\text { Reports }\end{array}$ & $\begin{array}{l}\text { c) Determine progress in } \\
\text { implementation of AQAP measures }\end{array}$ \\
\hline \multicolumn{3}{|c|}{$\begin{array}{l}\text { Step } 3 \text { - Determine whether there is any relationship between changes in local } \\
\text { road-contribution } \mathrm{NO}_{2} \text { (Step 1) and implementation of AQAP measures (Step 2) }\end{array}$} \\
\hline $\begin{array}{l}\text { a) Determine temporal associations } \\
\text { between implementation of AQAP } \\
\text { measures and changes in local road- } \\
\text { contribution } \mathrm{NO}_{2}\end{array}$ & $\begin{array}{l}\text { b) Determine spatial associations } \\
\text { between implementation of AQAP } \\
\text { measures and changes in local road- } \\
\text { contribution } \mathrm{NO}_{2}\end{array}$ & $\begin{array}{l}\text { c) Identify trends across all Round } 1 \\
\text { baseline AQMAs included in the final } \\
\text { sample }\end{array}$ \\
\hline
\end{tabular}

Figure 1: Methodological flow diagram.

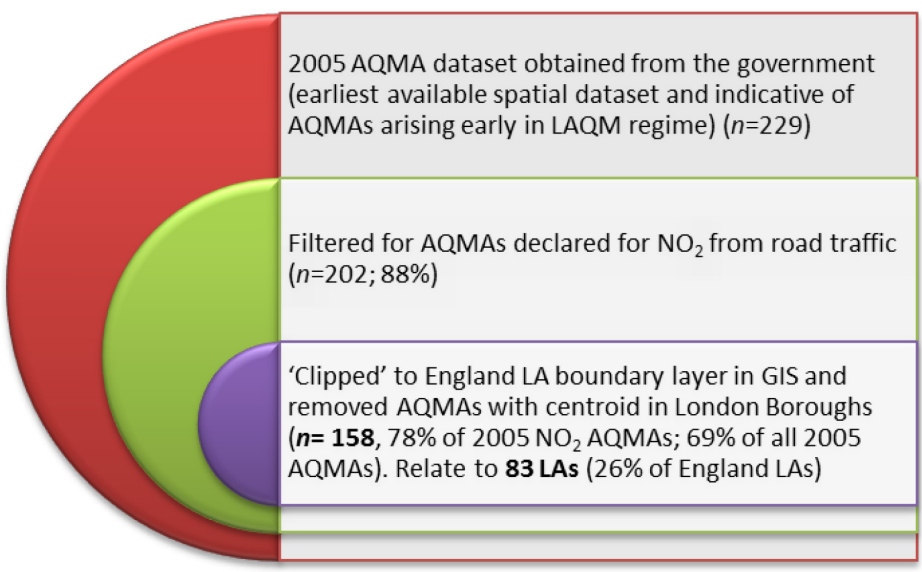

Figure 2: Initial sample filtering process.

using an attribute selection and exported as a separate shapefile. The London Boroughs and AQMAs relating to Scotland, Wales or Northern Ireland were removed and the remaining selection, representing the England $2005 \mathrm{NO}_{2}$ AQMAs, was exported as a new feature class. This layer contained 158 AQMAs over 83 local authorities (Figure 2). A comparison of this dataset with archived 
records of local authorities that had declared AQMAs following Round 1 revealed no major discrepancy and the spatial dataset was therefore taken as representative of AQMAs arising early in the LAQM regime.

\subsection{AQMAs in Zones and Agglomerations}

To determine which Zone/Agglomeration the England $2005 \mathrm{NO}_{2}$ AQMAs intersect, a spatial join was run with a Zones and Agglomerations shapefile obtained from the European Environment Agency (EEA) AirBase (v6) which represented the zones reported by Member States to the European Commission (EC) for exceedences of the $2010 \mathrm{NO}_{2}$ limit values (updated December 2012) (http://www.eea.europa.eu/data-and-maps/data/zones-in-relation-to-eu-air-quality -thresholds-4). As Zones and Agglomerations are unrelated to local authority boundaries, there were a number of AQMAs that intersected more than one Zone or Agglomeration. The analysis identified that the 158 AQMAs identified above fall within 21 of the 43 UK Zones and Agglomerations. The EEA GIS dataset also states which zones exceeded the 2010 limit values for $\mathrm{NO}_{2}$. There was only one zone in England that did not exceed the annual mean limit value (Blackpool Urban Area) and there were no AQMAs in Blackpool in the 2005 dataset. All remaining 2005 AQMAs were located within Zones or Agglomerations that were exceeding at least the annual mean limit value. The Greater London Urban Area zone also exceeds the hourly mean limit value, which includes 11 AQMAs in 8 local authorities from the 2005 dataset.

\subsection{Criteria for selecting AQMAs/local authorities}

The methodological approach, as set out in Figure 1, was to identify changes in local (road contribution) $\mathrm{NO}_{2}$ over the period of the implementation of AQAPs, the implementation of measures in related AQAPs, and to statistically assess any correlative relationship between them. It was therefore necessary to identify those local authorities and respective AQMAs with valid monitoring sites and $\mathrm{NO}_{2}$ annual mean data relevant to their AQMAs, and that have also published AQAPs and subsequent AQAP Progress Reports to enable the implementation of measures to be assessed. A series of criteria were established to identify those local authorities and AQMAs with the information required to apply the methodological approach (Figure 3).

\subsubsection{Criterion 1: compliance with Action Plan Progress Reporting requirements}

AQAPs pertaining to the 83 England local authorities identified as declaring an AQMA for $\mathrm{NO}_{2}$ by July 2005 were requested from Defra, resulting in AQAPs for 32 local authorities. Copies of reports that were unobtainable from Defra were sought from the local authorities' websites. In some instances reports for several local authorities were available on regional websites (e.g. Herts and Beds Air Quality Network) or in others combined reports for several local authorities had been produced (e.g. Greater Manchester). For those local authorities that have been subsumed within unitary authorities following the 2009 local 


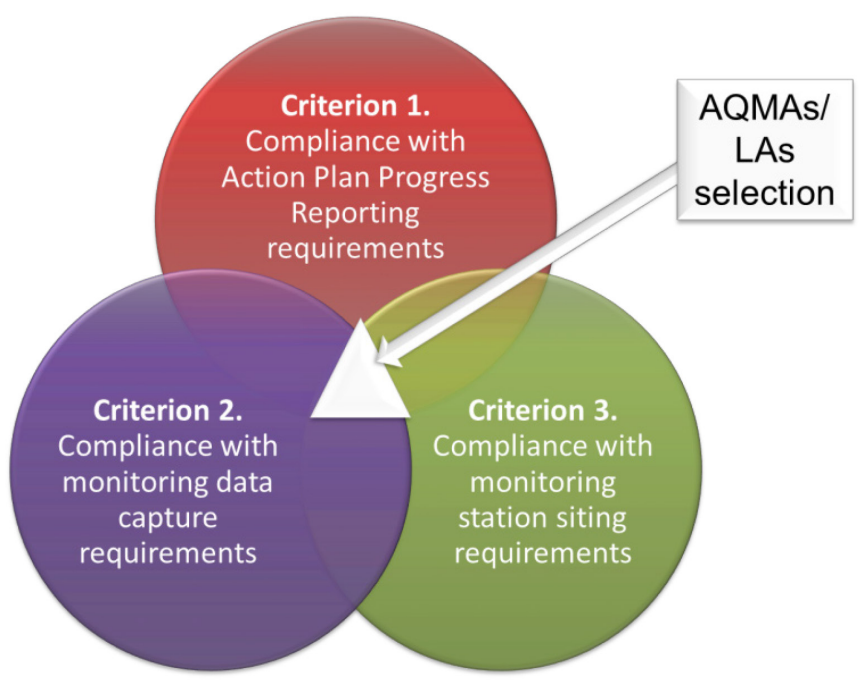

Figure 3: Criteria used to identify local authorities/AQMAs used in this study.

government restructure, historical reports were either unavailable (e.g. Shropshire Council) or were available grouped by local authority on the new unitary authority website (e.g. Wiltshire Council). An additional 44 AQAPs were obtained from local authorities' websites and a further six hard copy reports were available from previous projects (to give 82 in total). The date range of these AQAPs was from April 2002 (South Lakeland DC) up to March 2011 (Dudley $\mathrm{MBC}$ ). No AQAPs were obtainable for one of the 83 local authorities (South Oxfordshire DC).

As well as AQAPs, Updating and Screening Assessments (USAs) and Progress Reports, including Action Plan Progress Reports (AQAP PRs), from Rounds 2, 3, 4 and 5 were also downloaded from local authority websites where available.

To maximise the potential number of AQAPs available and ensure sufficient time had elapsed since their publication against which to measure implementation of the measures therein, criteria were set on the maximum cutoff date for publication of AQAPs as $31^{\text {st }}$ December 2005, and the minimum cut-off year for publication of AQAP PRs as 2009. These cut-off dates were based on the period over which reports were available (AQAPs: 2002-2011; AQAP PRs: 2004-2012) allowing a minimum of three years for the potential implementation of the original AQAP (Figure 4).

Of the 1582005 AQMAs, there were 105 of them (covering 55 local authorities) meeting the criterion for AQAP PRs (i.e. AQAPs published pre1/1/2006 and revised AQAPs, AQAP PRs or USAs containing AQAP PRs published in 2009 or later). 


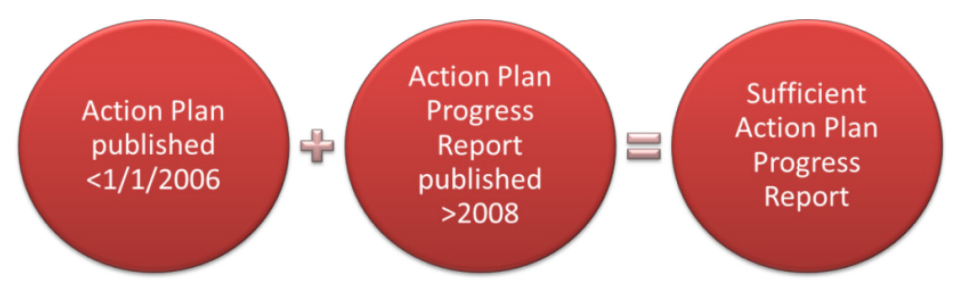

Figure 4: Criterion 1: compliance with Action Plan Progress Reporting requirements.

\subsubsection{Criterion 2: compliance with monitoring data requirements}

Data from the government's Automatic Urban and Rural Network (AURN) of monitoring sites were used as these data are reported to the EC against the limit values. Annual mean $\mathrm{NO}_{2}$ monitoring data with data capture $>75 \%$ for all 178 AURN sites from 1961-2012 was downloaded from the Defra AURN website (http://uk-air.defra.gov.uk/data/exceedence) and reshaped from 'long' to 'wide' format using $\mathrm{R}$ [8]. These data were filtered for sites with $>75 \%$ data capture for the period 2005-2012 (i.e. at least six years' data) to provide sufficient data to identify trends, leaving 77 sites (Figure 5). AURN site data from 1987-2010 was also downloaded (http://data.gov.uk//dataset/nitrogen-dioxide-annual-meancomparison-with-health-objective-for-2005-1987-to-2010). This dataset included UK and EU site type categorisations for each monitoring station, so the relevant fields from the two datasets were combined in a MS Access query. At the same time a query was run as a check to calculate any differences between annual means recorded in the respective datasets. Some minor discrepancies (up to $3 \mu \mathrm{g} / \mathrm{m}^{3}$ ) were noted relating to three London sites in 2010 , but these were not relevant to the study.

A number of AURN sites had been identified as not meeting the siting criteria specified in Annex V of the Directive 2008/50/EC [9] (Brighton Roadside, Bristol Old Market, Bury Roadside, Leicester Centre, London Cromwell Road 2, Sandwell West Bromwich). Of these sites all but Brighton Roadside were remaining in the filtered dataset. It was decided to retain these sites within the dataset at this stage in order not to restrict the potential number of AQMAs for which monitoring sites were available, however the questionable validity of data associated with these sites was noted.

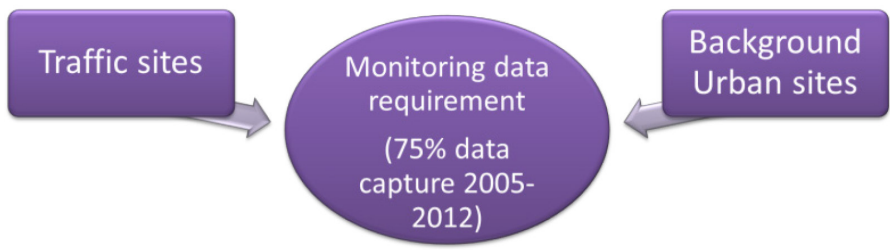

Figure 5: $\quad$ Criterion 2: compliance with monitoring data requirements. 


\subsubsection{Criterion 3: compliance with monitoring siting requirements}

Details and grid references of the 217 operational and 79 discontinued government monitoring sites were obtained from AEA Technology, who QA/QC the AURN network on behalf of Defra. The dataset of operational sites (as at February 2012) included sites from other monitoring networks so these were filtered in Excel to select only those 130 sites belonging to the AURN. There was insufficient information in the spreadsheet to filter the dataset further, i.e. by pollutant or country. The dataset of discontinued sites included only AURN sites, however the dataset was able to be filtered in Excel to select only those sites that had monitored $\mathrm{NO}_{2}$ and those that were in England, leaving 31 discontinued sites. Both filtered datasets were added to ArcView.

The 77 sites that met the data capture criterion (2) were joined to both the operational and closed AURN spatial datasets, keeping only matching records, using the sites names as the common field, to create spatial AURN datasets complete with annual mean $\mathrm{NO}_{2}$. This left 75 operational sites with sufficient data. Of the closed sites, only two (Sandwell West Bromwich and Northampton [both Urban Background sites]) were identified with sufficient data for the period in question. An overlap between the closed and operational site datasets was identified with Northampton appearing in both. Northampton was therefore removed from the joined closed site dataset. One site (Glasgow City Chambers), for which adequate data was available, did not appear in either the operational or closed site spatial datasets; given the distance between this background urban site and the most northerly England AQMA (Newcastle upon Tyne AQMA No. 1) is more than $5 \mathrm{~km}$, this was not considered to be a problem. The remaining one closed and 75 operational sites joined datasets were merged to form one feature class with 76 combined closed and operational AURN sites with $\mathrm{NO}_{2}$ annual mean concentrations with $>75 \%$ data capture between 2005 and 2012 .

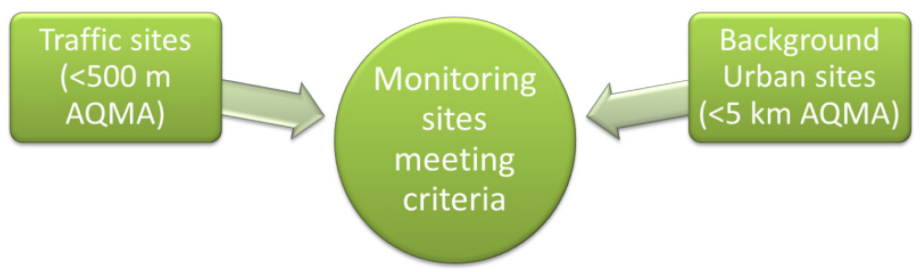

Figure 6: Criterion 3: compliance with monitor siting requirements.

From the merged dataset, sites were selected by EU site type (i.e. Traffic Urban and Background Urban). This was to enable the data from like sites to be compared, but also to ensure that the sites could be appropriately linked to the AQMAs to enable calculation of the local traffic contribution, i.e. Traffic Urban sites identified within (or a short distance of) AQMAs to reflect the immediate characteristics of the exceedence area, but Background Urban sites representative of the wider urban area, the difference in concentrations being attributable to the local road traffic over which local authorities' may have some impact. Airport and Industrial Urban sites indicate the potential for sources other than road 
transport to affect local air quality, which may render AQMAs, and associated AQAPs, within the vicinity to be deemed unrepresentative and therefore nonapplicable to other road transport-based AQMAs. A selection by location revealed that there were no Airport AURN sites within the 2005 AQMAs but there were two Industrial Urban sites: Salford Eccles in the Salford AQMA and Sheffield Tinsley in the Sheffield M1 Corridor Air Action Zone AQMA.

A 'one-to-many' spatial join was carried out on each of the AURN site types that met the data criteria with the 2005 AQMA dataset to identify 'Traffic' and 'Background Urban' AURN sites within a certain distance of AQMAs. Distances of $0.5 \mathrm{~km}$ for Traffic sites and $5 \mathrm{~km}$ for Background Urban sites (Figure 6) were used based on an interpretation of the macroscale siting criteria detailed in Annex V (B.1) of Directive 2008/50/EC and site type definitions on the Defra UK-Air website (http://uk-air.defra.gov.uk/networks/site-types). These distances are also supported by the literature which suggests that background concentrations are generally reached within $500 \mathrm{~m}$ of the road [10].

There were only four Traffic Urban AURN sites within $500 \mathrm{~m}$ of four AQMAs. These are representative of four local authorities with Traffic Urban AURN sites within, or within $500 \mathrm{~m}$ of, their 2005 AQMAs with adequate data for the period 2005-2012. There were 15 Background Urban AURN sites within $5 \mathrm{~km}$ of 38 AQMAs. This represents 23 separate local authorities with AURN Background Urban sites within $5 \mathrm{~km}$ of their $2005 \mathrm{AQMA}(\mathrm{s})$ with adequate data for the period 2005-2012. There are only two local authorities with both suitably sited Traffic Urban and Background Urban AURN sites (Bristol City Council and Bury Metropolitan Borough Council), however, the Traffic Urban sites identified for these authorities did not meet the EU siting criteria [9].

\subsubsection{AQMAs/LAs that comply with all selection criteria}

Of the 1582005 AQMAs, there were 105 (covering 55 local authorities) that met the AQAP Progress Report criteria. Of these 105 there was only one (Bristol AQMA) that met the monitoring data criteria and siting criteria for both Traffic Urban and Background Urban sites (though the Traffic Urban site has been deemed to be non-compliant with EU siting criteria) [9]. There was one AQMA (Oxford AQMA) that met the monitoring data and siting criteria for Traffic Urban sites only and 25 that met monitoring and siting criteria for Background Urban sites only.

Having passed through each of the three criteria (i.e. AQAP PRs criterion, monitoring data criterion and siting criterion), there is only one AQMA that meets all three criteria with both a Traffic Urban site and Background Urban site to allow calculation of the local road contribution to $\mathrm{NO}_{2}$; one meeting the criteria for a Traffic Urban site only; and 25 AQMAs across 14 local authorities that met the criteria for Background Urban sites only. Using the AURN sites, therefore, there is insufficient data available to calculate the local contribution to $\mathrm{NO}_{2}$ and therefore the effectiveness of the AQAP implementations to reduce local $\mathrm{NO}_{2}$. 


\subsection{Next steps}

Local authority Traffic sites will be identified for those AQMAs that have suitable AURN Background Urban sites. To ensure the most comparable data are used, these should be automatic monitors that have been correctly QA/QC'd according to Defra Technical Guidance [11]. As far as possible sites should be selected on the basis of their consistency with micro- and macro-scale siting criteria as defined in Annex V of Directive 2008/50/EC. Information about the availability and location of local authority Traffic monitoring sites, the sufficiency of monitoring data and the adequacy of the QA/QC procedures will be obtained from the LAQM reports (USAs and Progress Reports). Further local authority automatic monitoring data from the LAQM reports for both Traffic and Background sites for those authorities that met the AQAP PR criteria will also be obtained to give a potential additional 78 AQMAs over 40 local authorities.

Once adequate monitoring sites and data are identified, the local contribution to $\mathrm{NO}_{2}$ in each AQMA (Traffic $\mathrm{NO}_{2}$ minus Background $\mathrm{NO}_{2}$ ) will be calculated to determine whether there is any change in local $\mathrm{NO}_{2}$ between 2005 and 2012 in each AQMA. The AQAPs and AQAP Progress Reports for these local authorities will then be examined to identify any measures that have been implemented, and case studies for each local authority meeting the selection criteria will be produced to identify any correlation between local $\mathrm{NO}_{2}$ and AQAP implementation.

\section{Results}

This paper has set out the process used to identify the sample of AQMAs and local authorities which met a series of criteria that would enable the broader research methodology to be undertaken. Figure 7 summarises the results of this process, showing each of the filtering stages and the sample number of AQMAs, with the number of local authorities in brackets.

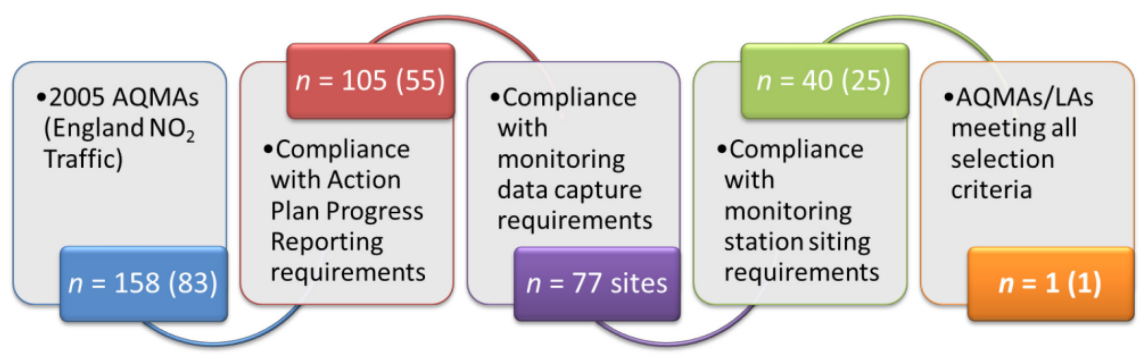

Figure 7: Summary flow diagram.

In the first stage, the AQMA spatial dataset was filtered for those AQMAs in England that had been declared for $\mathrm{NO}_{2}$ from traffic sources. This reduced the 229 AQMAs declared by July 2005 to 158 over 83 local authorities. In the second stage, three criteria were required to be met in each AQMA in order to 
calculate the local road contribution to the $\mathrm{NO}_{2}$ annual mean and determine whether any measures had been implemented in the local AQAPs:

- Criterion 1: compliance with Action Plan Progress Reporting requirements.

- Criterion 2: compliance with monitoring data requirements.

- Criterion 3: compliance with monitoring siting requirements.

Of the 158 AQMAs over 83 local authorities, 105 over 55 local authorities were found to meet criterion 1, i.e. published AQAPs before 1/1/2006 and AQAP Progress Reports after 2008. Annual mean $\mathrm{NO}_{2}$ data for the government's 178 AURN sites were downloaded and of these, 77 were found to meet the data requirements of criterion 2 , i.e. data capture of $75 \%$ or more between 2005 and 2012. Joining the sites with adequate data to the spatial dataset obtained for the monitoring sites revealed 76 sites that met criterion 2. The third criterion identified whether the monitoring sites were within the vicinity of the AQMAs. Traffic Urban sites within $0.5 \mathrm{~km}$ of an AQMA and Background Urban sites within $5 \mathrm{~km}$ were selected. From the 158 AQMAs over 83 local authorities this left only 40: 2 AQMAs with both Traffic Urban and Background Urban sites (Bristol AQMA and Bury AQMA), two with Traffic Urban sites only (Bath AQMA, Oxford AQMA) and 36 with Background Urban sites only. Of the 158 2005 AQMAs, therefore, there are 118 AQMAs (75\%) which have no suitably located AURN sites with sufficient data for the period 2005-2012. Linking these back to the 105 AQMAs over 55 local authorities that met criterion 1, only one site (Bristol AQMA) met all three criteria, i.e. sufficient AQAP and AQAP Progress Reports, adequate monitoring data and suitably sited Traffic Urban and Background Urban sites. It should be noted, however, that the Traffic Urban site (Bristol Old Market) had been identified as not meeting EU siting criteria [9].

\section{Discussion}

The findings of this research so far tell us much about the ineffectiveness of LAQM in relation to the government's responsibility to meet EU air quality legislation. It is clear that, despite the opportunity that LAQM provided to assist the government with achievement of the EU limit values, the process was never calibrated sufficiently to provide a measureable contribution. There are several factors that have been identified in this research to corroborate this statement.

Firstly, the Zones and Agglomerations that the government devised in response to the Air Quality Framework Directive (96/62/EC) are not coterminous with local authority boundaries or the AQMAs. If there was ever any intention to allow local authorities' AQMAs to feed into national reporting to the EC this fundamental step could have been taken.

Second, there are insufficient government monitoring sites available to gauge progress against EU limit values in AQMAs. This research has shown that only one AQMA had adequately sited Traffic Urban and Background Urban AURN sites available, and even this Traffic Urban site had been shown not to be compliant with EU siting criteria. The government could have established 
AURN sites in each AQMA in order to assess changes in concentrations of the key pollutants, e.g. $\mathrm{NO}_{2}$, against which progress in the local AQAPs and national measures may be assessed.

Thirdly, local authority monitoring sites are not required to be compliant with EU siting or operational criteria. Many local authorities operate automatic monitoring within their AQMAs and are required to adhere to QA/QC procedures to qualify the use of that data in their LAQM reporting. If siting AURN monitors within all of the AQMAs was not feasible, the government could have ensured that LAQM monitoring QA/QC procedures were in line with those required by the EC, thereby increasing the network of reportable monitoring data that could be used to determine progress made on local and national actions within AQMAs.

Fourthly, the requirement for local authorities to produce AQAPs (within 18 months of declaration of an AQMA) and annual AQAP PRs is not enforced. This research found that many local authorities that had declared AQMAs had not published AQAPs within the specified timescale or within a number of years in some cases. Similarly, progress on the AQAPs is required annually, but there was an absence of annual AQAP Progress Reports found in this study. This is perhaps one of the most significant failings, as without the ability to gauge progress on measures implemented at a local level, neither national nor local government can show whether LAQM is working to improve local air quality.

\section{Conclusion}

In conclusion, the interim findings from this research have indicated that LAQM is insufficiently calibrated to provide adequate support to the achievement of the $\mathrm{NO}_{2}$ EU limit value.

\section{References}

[1] Great Britain. The Air Quality Regulations 1997 3043. London. Available from: http://www.legislation.gov.uk/uksi/1997/3043/made, 1997.

[2] Department of the Environment, The United Kingdom National Air Quality Strategy. London: DoE, 1997.

[3] Department for the Environment, Transport and the Regions, The Air Quality Strategy for England, Scotland, Wales and Northern Ireland. London: DETR, 2000.

[4] DETR. Department for Transport, Road Traffic Statistics - Annual Road Traffic Estimates 2010. London: National Statistics, 2012.

[5] Defra, Air Quality Plans for the Achievement of EU Nitrogen Dioxide $\left(\mathrm{NO}_{2}\right)$ Limit Values in the UK: UK Overview Document. London: The Stationery Office, 2011.

[6] Moorcroft, S. and Dore, C., 2013. Review of Effectiveness of Local Authority Action Plans and Future Policy Options for LAQM. Report number: 1372/1/F1.Defra. 
[7] Chatterton, T.J., Woodfield, N.K., Beattie, C.I. and Longhurst, J.W.S., 2004. Outcomes of the first round of local authority air quality Review and Assessments under the UK's air quality strategy. Journal of Environmental Monitoring: JEM. 6 (10), pp. 849-853.

[8] R Core Team (2012). R: A language and environment for statistical computing. R Foundation for Statistical Computing, Vienna, Austria. ISBN 3-900051-07-0, URL http://www.R-project.org/.

[9] AEA, 2010. Automatic Urban \& Rural Network: Assessment of Siting Criteria. Report number: AEAT/ENV/R/2858- Issue 2.Defra.

[10] Baldauf, R., Watkins, N., Heist, D., Bailey, C., Rowley, P. and Shores, R., 2009. Near-road air quality monitoring: Factors affecting network design and interpretation of data. Air Quality Atmospheric Health. 2 pp. 1-9.

[11] Defra, 2009. Part IV of the Environment Act 1995 [Environment (Northern Ireland) Order 2002 Part III] Local Air Quality Management Technical Guidance LAQM.TG(09). London: Department for Environment, Food and Rural Affairs. 